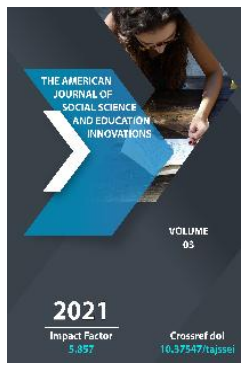

Journal Website: http://theamericanjour nals.com/index.php/taj ssei

Copyright: Original content from this work may be used under the terms of the creative commons attributes 4.0 licence.

\section{Women In Medicine - Gender Aspects}

Nigora Salieva

Teacher Of The Department Of Pedagogy And Physical Education Of The Fergana Medical Institute Of Public Health, Uzbekistan

Ulugbek Saliev

Candidate Of Historical Sciences, Senior Lecturer Of The Fergana Medical Institute Of Public Health, Uzbekistan

\title{
ABSTRACT
}

Respect for women is a noble quality inherent in our people. A worthy encouragement of the role and work of women in the upbringing of a healthy and harmoniously developed generation, the creation of the best conditions for them are among the priority directions of state policy. Widely used in the world community, the concept of "gender equality" implies the equal participation of men and women in all spheres of state and public life, in particular, in governance, decision-making and the security sector. A solid legal basis for equality between women and men has been created in our country. Their equality is enshrined in the Constitution. Labor law also provides for gender equality. As a result of the large-scale reforms being implemented in the country, the place of women in the socio-economic sphere is increasingly being strengthened.

\section{KEYWORDS}

Gender stratification, egalitarianism, polyfunctionality, gender preferences, gender-based, gender equality, communication style, gender-oriented approach, psychosocial, socialization.

\section{INTRODUCTION}


One of the priority directions of the state policy of the new Uzbekistan is the achievement of

gender equality, ensuring the rights, freedoms and legitimate interests of women, strengthening their role in public and state life. The observed trends in Uzbekistan in this area are in line with the global processes of expanding the representation of women at the highest levels of government, eliminating gender inequality, increasing the number in parliament, government and the judiciary. Today in Uzbekistan, a woman plays a key role in building a new civil society and developing all spheres of public life, which contributes to the formation of a gender-oriented approach in various areas, including in the health care system. Statistical data on the number of medical personnel in Uzbekistan: total medical doctors - 91.9 thousand people. 44.3 thousand of them are women doctors, and the number of nurses is 365.6 thousand people, women 333.4 thousand people [1].

\section{MATERIAL AND METHODS}

Reforms of a socio-economic nature carried out in Uzbekistan have largely changed the level of women's activity. A woman in medicine, on an equal basis with men, achieves success, despite her responsibilities to her family, raising children and improving her home. But at the same time, gender stratification between women and men persists in the health care system: men occupy leading positions, and women are engaged in direct practical work with patients. Differences in communication styles between female and male doctors lead to the conclusion that female doctors are more adaptive and their work as first aid workers is more preferable. The overwhelming majority of nurses are women. In the structure of the health care system in Uzbekistan, as in a number of CIS countries of the former postSoviet space, most of the doctors who are in key positions - rectors of medical universities, chief doctors of hospitals and leading research centers - continue to be occupied by men, most of the women doctors are employed in providing first aid to patients. At the same time, the communication style of women doctors and patients is characterized by a greater degree of egalitarianism and is aimed at solving the psychological problems of the patient. The medical professions are mostly female, but the careers in medicine are usually made by men.

\section{DISCUSSION AND CONCLUSION}

The studies carried out in the field of medicine by specialists dealing with gender issues state the following: female doctors experience greater difficulties, in comparison with men, in mastering the medical profession, they see the reasons for this both in the multifunctionality of their social role and in the prejudices existing in society. Female doctors have no gender preference for patients, but they believe they are more likely to deal with female patients than with men; female doctors are convinced that patients of both sexes trust a female doctor more than a male doctor; female doctors believe that they understand patients better and are able to empathize with them more than men; women Nowadays doctors believe that in medicine there are purely "female" and purely "male" specialties, moreover, "female" specialties are called more than "male"; women recognize the leading role of men in medicine, but do not consider this state of affairs to be correct; every female doctor considers her specialty to be "female".

The position of women in modern society in Uzbekistan is assessed by most researchers as insufficient, while most of them positively assess the desire of individual women to occupy a prominent public place. Consequently, the predominance of women in the structure of providing first aid in medical institutions is gender-based. 
Organized efforts of the Government and the President of Uzbekistan have become the reason that the health care system has become more attentive to the problems of women's health. A gender-sensitive health care system is desirable for Uzbekistan, but it will not be fundamentally different from the current one if women doctors do not use their knowledge and prestige to change it.

The overwhelming majority of nurses are women, their training and work in itself focus on helping patients, solving their psychosocial and biomedical problems. The nurses working in the hospitals take orders from the doctors. The collaboration of female doctors and nurses can make the entire medical practice more patient-centered as such.

Women doctors, like nurses, devote more time to talking with patients about psychosocial problems, their views on the course of treatment, they enable patients to ask more and challenge decisions made by doctors. The above mentioned differences in communication styles between women and men doctors allow us to conclude that women doctors are more human and their work as medical workers providing first aid to patients is more preferable.

The transformed healthcare system in Uzbekistan does not focus on the emotional and social needs of the patient, it does not give the patient more freedom in making decisions about the use of certain methods during his treatment. Women in high positions in the health care system may adopt a similar value system and criticize traditional medicine, or hold a standard view. In medicine, female doctors in Uzbekistan overcome the same difficulties as in any other country in the world. These are family issues, social burden, material component and more.

The first problem that could negatively affect the assessment of the role of women in medicine is the problem of gender preferences. But it turned out that the opinion of female doctors does not contain fundamental gender orientations, in other words, they do not think that there are more women among patients, because they pay more attention to them. Women doctors believe that patients trust them more than men. If a man is more of a specialist doctor, head of a department, or, at least, a specialist of the highest category, then a woman doctor is a local therapist, a less qualified worker. Women doctors rely more on the trust of their patients. Psychologically, trust in a female doctor is provided by the mechanisms of socialization.

However, there may be another explanation related to the psychology of women doctors themselves, women doctors in most cases are sure that they understand patients better and empathize with them than men. The gender division for medical specialties is quite obvious for the majority of women doctors in Uzbekistan: gynecologists, pediatricians, therapists, oncologists and psychotherapists. In recent years of health care reform in Uzbekistan, female doctors have received equal opportunities for career growth, selfrealization and participation in the public and political life of the country, but nevertheless, there are still persistent beliefs in society that the family distracts a woman from work, and the man, on the contrary, stabilizes and activates. Also in society, beliefs about the intellectual priority of men prevail.

\section{ACKNOWLEDGEMENT}

A solid legal basis for equality between women and men has been created in our country. Their equality is enshrined in the Constitution. Labor law also provides for gender equality. However, despite this, in fact, the opportunities for women to find a decent place in the labor market in some areas are limited. Please note that to date, Uzbekistan has never been included in the list of 150 countries in terms of gender differences. This 
fact alone is the basis for the assertion that work in this direction is insufficient. From this point of view, the Law "On guarantees of equal rights and opportunities for women and men", adopted on September 2, 2019, laid the foundation for sustainable development of the country, the development of targeted programs aimed at specific goals, and the achievement of important results in based on the principles specified in the law.

\section{REFERENCES}

1. Baratova S. "In Uzbekistan, women will never be discriminated against", 2019.

2. Saidov A. "Gender policy of the new Uzbekistan in the context of international trends in parliamentarism" - Tashkent, 19.03.2021.

3. Kovaleva MD Women in medicine: Monograph - Volgograd 2004 - 12.5 sq.

4. Kovaleva MD, Shlyapnikova MN Gender studies and medicine // Sociology of medicine - 2003 - № 1 (2). - 0.5 pcs.

5. Kovaleva MD Gender problems in medical science -Volgograd, 2003.-1,5 pl.

6. Kovaleva M.D. Features of the gender approach in medicine // Science, art, education in the III millennium-Volgograd, 2003. 